\title{
Effects of a leucine and pyridoxine-containing nutraceutical on body weight and composition in obese subjects
}

This article was published in the following Dove Press journal:

Diabetes, Metabolic Syndrome and Obesity:Targets and Therapy

22 August 2013

Number of times this article has been viewed

\author{
Michael B Zemel ${ }^{1,2}$ \\ Antje Bruckbauer' \\ 'NuSirt Sciences, Inc., \\ ${ }^{2}$ Nutrition Department, \\ The University of Tennessee, \\ Knoxville, TN, USA
}

Correspondence: Michael B Zemel NuSirt Sciences, Inc., I 1020 Solway School Road, Suite 109, Knoxville, TN 3793I, USA

Tel +l 8652066154

Email mzemel@nusirt.com
Background: We recently demonstrated leucine to modulate energy partitioning between adipose tissue and muscle. Further, leucine exhibits a synergy with B6, resulting in reduced adipocyte lipid storage coupled with increased muscle fat oxidation. Accordingly, a nutraceutical (NuShape ${ }^{\mathrm{TM}}$ ) containing $2.25 \mathrm{~g}$ leucine and $30 \mathrm{mg} \mathrm{B} 6$ increased fat oxidation by $>30 \mathrm{~g} /$ day in a 28-day randomized controlled trial. The present study evaluated the long-term efficacy of this combination in modulating body weight and composition.

Methods: Two 24-week, placebo-controlled, randomized trials, one with weight maintenance $(\mathrm{n}=20)$ and one hypocaloric $(-500 \mathrm{kcal} / \mathrm{day} ; \mathrm{n}=24)$, were conducted using the nutraceutical Nushape in obese subjects.

Results: The supplement resulted in fat loss in the maintenance study $(-1.12 \pm 0.36$ and $-1.82 \pm 0.70 \mathrm{~kg}$ at 12 and 24 weeks, $P<0.01$ versus placebo) while no change was found in the placebo group. In the hypocaloric study, the supplement group lost up to twice as much weight $(6.18 \pm 1.02$ versus $3.40 \pm 0.81 \mathrm{~kg}$ at 12 weeks and $8.15 \pm 1.33$ versus $5.25 \pm 1.13 \mathrm{~kg}$ at 24 weeks, $P<0.01)$ and fat $(4.96 \pm 0.61$ versus $2.31 \pm 0.53 \mathrm{~kg}$ at 12 weeks and $7.00 \pm 0.95$ versus $4.22 \pm 0.74 \mathrm{~kg}$ at 24 weeks, $P<0.01$ ) than the placebo group.

Conclusion: This nutraceutical combination results in significant fat loss in the absence of caloric restriction and markedly enhances weight and fat loss by $50 \%-80 \%$ over a 24 -week period.

Keywords: leucine, vitamin B6, pyridoxine, fat loss, weight loss, caloric restriction, adiposity, body composition

\section{Background}

Recent data from this and other laboratories demonstrate a significant role for leucine in modulating fat oxidation and energy partitioning between adipose tissue and skeletal muscle, resulting in reductions in adipose tissue lipid storage, increased net fat oxidation, and reduced adiposity. ${ }^{1-5}$ These effects are mediated, in part, by sirtuin (SIRT)1-dependent pathways. ${ }^{2}$ We have shown leucine to activate SIRT1 signaling directly in a cell-free system, ${ }^{6}$ as well as in both adipocytes and skeletal muscle cells. ${ }^{2,7}$ Moreover, knockdown of SIRT1 attenuates leucine-induced increases in mitochondrial biogenesis, oxygen consumption, and fat oxidation. ${ }^{2}$

We have also recently shown leucine to interact synergistically with vitamin B6 to attenuate adiposity. ${ }^{8}$ Pyridoxal phosphate inhibits adipocyte $\mathrm{Ca}^{2+}$ influx in vitro, ${ }^{8}$ resulting in significant decreases in adipocyte fatty acid synthase expression and activity and corresponding reductions in adipocyte triglyceride content, ${ }^{8}$ because $\mathrm{Ca}^{2+}$ signaling coordinately stimulates fatty acid synthase activity and inhibits 
lipolysis in adipocytes. ${ }^{9-13}$ Moreover, leucine and pyridoxal phosphate synergistically inhibit adipocyte triglyceride accumulation. ${ }^{8}$ Consequently, the efficacy of a leucine (2.25 g/day)-B6 (30 mg pyridoxine/day) combination in stimulating fat oxidation in vivo was evaluated in a 28-day, placebo-controlled, randomized clinical trial with overweight and obese subjects and found to increase whole-body fat oxidation significantly by $>30$ g/day. ${ }^{8}$ However, this trial was of too short a duration to determine the efficacy of this combination in modulating body weight and composition. Accordingly, we conducted the present study to determine the efficacy of a leucine/pyridoxine nutraceutical combination in augmenting body weight and fat loss during mild caloric restriction and in modulating body composition in the absence of caloric restriction.

\section{Materials and methods}

Two 24-week, placebo-controlled, parallel-group, doubleblind, randomized trials were conducted, as described below. The first evaluated the effects of the supplement in subjects under mildly hypocaloric conditions and the second evaluated the effects of the supplement under weight maintenance conditions. Other than caloric restriction, procedures were identical for the two trials.

\section{Design of both trials}

Twenty obese subjects (14 females and six males aged $26.82 \pm 4.24$ years, body mass index $\left.34.76 \pm 2.57\left[\mathrm{~kg} / \mathrm{m}^{2}\right]\right)$ for the hypocaloric trial and twenty-four obese subjects (12 females, 12 males aged $25.73 \pm 4.89$ years, body mass index $35.92 \pm 2.85\left[\mathrm{~kg} / \mathrm{m}^{2}\right]$ ) for the maintenance trial were randomized to receive either the active supplement, termed NuShape $^{\text {TM }}$ (NuSirt Sciences, Inc., Nashville, TN, USA) or placebo twice daily. Subject characteristics at baseline are shown in Table 1. Each dose of the active blend provided $1.125 \mathrm{~g}$ leucine and $15 \mathrm{mg}$ pyridoxine, for a total daily dose of $2.25 \mathrm{~g}$ leucine and $30 \mathrm{mg}$ pyridoxine.

Subjects were studied for a 7-day lead-in period to establish their current caloric requirements, as described below (diets) and then placed on either a hypocaloric diet (500 kcal/day reduction from maintenance, study 1) or a maintenance diet (study 2) and randomized to active treatment or placebo for 24 weeks. Body weight, waist circumference, and body fat were measured at baseline and at the end of weeks 12 and 24, with subjects wearing street clothes. Body fat was measured using dual X-ray absorptiometry. Fasting levels of circulating insulin, glucose, and fasting plasma
Table I Baseline subject characteristics

\begin{tabular}{|c|c|c|c|}
\hline $\begin{array}{l}\text { Hypocaloric } \\
\text { diet }\end{array}$ & All subjects & Placebo & NuShape $^{\mathrm{TM}}$ \\
\hline Age (years) & $26.82 \pm 4.24$ & $24.38 \pm 5.18$ & $29.26 \pm 5.63$ \\
\hline Weight (kg) & $86.03 \pm 9.11$ & $88.09 \pm 9.02$ & $83.97 \pm 10.36$ \\
\hline BMI $\left(\mathrm{kg} / \mathrm{m}^{2}\right)$ & $34.76 \pm 2.57$ & $35.10 \pm 2.82$ & $34.42 \pm 3.00$ \\
\hline Body fat $(\mathrm{kg})$ & $29.44 \pm 3.98$ & $30.38 \pm 4.42$ & $28.51 \pm 4.26$ \\
\hline $\begin{array}{l}\text { Waist } \\
\text { circumference }(\mathrm{cm})\end{array}$ & $91.06 \pm 11.25$ & $94.73 \pm 10.32$ & $87.39 \pm 12.04$ \\
\hline $\mathrm{HOMA}_{\mathrm{IR}}$ & $2.65 \pm 0.18$ & $2.71 \pm 0.45$ & $2.59 \pm 0.21$ \\
\hline Gender & $14 \mathrm{~F} / 6 \mathrm{M}$ & $7 \mathrm{~F} / 3 \mathrm{M}$ & $7 \mathrm{~F} / 3 \mathrm{M}$ \\
\hline $\begin{array}{l}\text { Maintenance } \\
\text { diet }\end{array}$ & All subjects & Placebo & NuShape \\
\hline Age (years) & $25.73 \pm 4.89$ & $28.02 \pm 5.95$ & $23.44 \pm 5.62$ \\
\hline Weight (kg) & $92.95 \pm 8.62$ & $91.74 \pm 9.02$ & $94.16 \pm 8.53$ \\
\hline BMI $\left(\mathrm{kg} / \mathrm{m}^{2}\right)$ & $35.92 \pm 2.85$ & $36.67 \pm 2.22$ & $35.17 \pm 2.31$ \\
\hline Body fat (kg) & $34.70 \pm 3.74$ & $34.66 \pm 4.05$ & $34.74 \pm 3.46$ \\
\hline $\begin{array}{l}\text { Waist } \\
\text { circumference }(\mathrm{cm})\end{array}$ & $95.38 \pm 9.63$ & $94.06 \pm 8.24$ & $96.70 \pm 10.15$ \\
\hline $\mathrm{HOMA}_{\mathrm{IR}}$ & $2.77 \pm 0.29$ & $2.93 \pm 0.47$ & $2.61 \pm 0.33$ \\
\hline Gender & $12 \mathrm{~F} / 12 \mathrm{M}$ & $6 \mathrm{~F} / 6 \mathrm{M}$ & $6 \mathrm{~F} / 6 \mathrm{M}$ \\
\hline
\end{tabular}

Note: Data are expressed as the mean \pm standard deviation.

Abbreviations: $\mathrm{BMI}$, body mass index; $\mathrm{HOMA}_{\mathbb{R}}$, homeostatic assessment of insulin resistance; $F$, female; $M$, male.

lipids (triglycerides, total cholesterol, and high-density lipoprotein cholesterol) were measured at the same time points (baseline and at weeks 12 and 24).

All subjects were weight-stable by self-report for the 4 weeks preceding study initiation and met the following exclusion criteria: significant endocrine, metabolic, or gastrointestinal disease; obesity pharmacotherapy (prescription or over-the-counter) within the preceding 4 weeks; pregnancy or lactation; initiation or change in a diet or exercise program within the preceding 4 weeks; changes in pattern of tobacco use; or use of psychotropic medications within the past 4 weeks. Both studies were approved from an ethical standpoint by the institutional review board of The University of Tennessee, Knoxville.

\section{Diet}

Baseline dietary assessments (diet records) were conducted during the lead-in period and were used to provide an initial estimate of a maintenance level of energy intake, which was then refined by calculating needs using World Health Organization equations for calculation of basal metabolic rate, adjusted for activity level to provide an estimate of total daily energy expenditure. Total daily energy expenditure was calculated as $1.3 \times$ basal metabolic rate for all subjects, because all were sedentary. Discrepancies between estimated total 
daily energy expenditure and baseline caloric intake were resolved, if necessary, by repeat diet records. Based on this initial estimate of caloric needs, a food exchange-based diet was developed for each subject to produce a caloric deficit of approximately $500 \mathrm{kcal} /$ day for the hypocaloric study or to produce weight maintenance for the maintenance study. The diets were constructed to provide comparable levels of macronutrient and fiber, to approximate the average consumption in the US (fat, approximately $35 \%$ of total energy, carbohydrates approximately $49 \%$, approximately protein $16 \%$, fiber $2-3 \mathrm{~g} / 1,000 \mathrm{~kJ} /$ day). Nutritional supplements were not permitted, and caffeine intake was maintained at a constant level (individualized for each patient, according to baseline assessment). Diets were prescribed and monitored as noted above.

Subjects were provided with individual instruction regarding dietary adherence, and compliance was assessed by weekly subject interview and review of the 3-day diet diaries. There were no significant differences in energy and macronutrient intake between treatments for either trial.

\section{Anthropometric measurements}

Body weight and waist circumference were measured weekly, with subjects wearing street clothes, with no shoes, outerwear, or accessories. Body weight was measured with a calibrated scale. Height was measured with a wallmounted stadiometer. Waist circumference was measured in the standing position with measurements obtained midway between the lateral lower rib margin and the iliac crest. Two measurements were taken mid-exhalation and the average was recorded.

\section{Body composition}

Total fat mass was assessed by dual-energy X-ray absorptiometry at baseline, 12 weeks, and 24 weeks. A Lunar Prodigy ${ }^{\mathrm{TM}}$ dual-energy X-ray absorptiometry system (GE Healthcare, Madison, WI, USA) maintained and calibrated by Lunar staff annually was used. A spine phantom was assessed every day to determine whether any drift in the machine occurred, followed by the daily calibration block; the spine phantom variation was $<3 \%$ throughout the study.

\section{Statistical analysis}

Data were evaluated for significance by two-way (treatment $x$ time) analysis of variance SAS-PC (SAS 9.2, SAS Institute, Cary, NC, USA). Criteria for parametric analysis (normality of distribution and homogeneity of variance) were confirmed prior to analysis. Data are reported as the mean \pm standard deviation.

\section{Results}

There were no significant differences in energy or macronutrient intake between the placebo and supplement groups. Energy intake in the hypocaloric trial was $1429 \pm 291$ (placebo) and $1487 \pm 310$ (supplement) kcal/day, and energy intake in the maintenance trial was $2018 \pm 462$ (placebo) and $2073 \pm 413$ (supplement) kcal/day.

All subjects in the hypocaloric diet trial lost weight, fat, and waist circumference $(P<0.01)$. However, the supplement group lost $82 \%$ more weight and more than twice as much body fat at 12 weeks $(P<0.01$, Table 2$)$; these differences were sustained through the conclusion of the study, with the supplement resulting in increases in body weight and fat loss of $55 \%$ and $66 \%$, respectively $(P<0.01$, Table 2$)$. These differences were reflected in an augmented decrease in waist circumference in the supplemented group which was evident within 4 weeks of treatment (Table 3); the supplemented group showed an approximately 3 -fold greater loss of waist circumference at 4 weeks $(P<0.01$, Table 3$)$, which was sustained as a 2 -fold greater loss of waist circumference at the 24-week endpoint $(P<0.01$, Table 3).

Subjects in the weight maintenance trial did not exhibit any significant changes in body weight regardless of treatment, consistent with the experimental design. However, subjects in the supplemented group exhibit significant losses of body fat at 12 weeks, with additional fat loss at 24 weeks $(P<0.01)$, while body fat loss in the placebo group was not significantly different from baseline at either time point (Table 4).

The supplements exerted no significant effect on plasma glucose, but plasma insulin decreased significantly during weight loss in both the placebo and NuShape groups (Table 5). However, the NuShape group exhibited a

Table 2 Effects of NuShape ${ }^{\mathrm{TM}}$ on body weight and fat in subjects on an energy-restricted diet

\begin{tabular}{llll}
\hline $\begin{array}{l}\text { Change from } \\
\text { baseline (kg) }\end{array}$ & I 2 weeks & 24 weeks & $\begin{array}{l}\text { Significance } \\
\text { versus placebo }\end{array}$ \\
\hline $\begin{array}{l}\text { Weight } \\
\text { Placebo }\end{array}$ & $-3.40 \pm 0.81$ & $-5.25 \pm 1.13$ & $* P<0.01$ \\
$\quad$ NuShape & $-6.18 \pm 1.02 *$ & $-8.15 \pm 1.33 *$ & \\
Fat & & & \\
$\quad \begin{array}{l}\text { Placebo } \\
\text { NuShape }\end{array}$ & $-2.31 \pm 0.53$ & $-4.22 \pm 0.74$ & $* P<0.01$ \\
\hline
\end{tabular}

Notes: Data expressed as the mean \pm standard deviation change from baseline; *Significance versus placebo. 
Table 3 Effects of NuShape ${ }^{\mathrm{TM}}$ on loss of waist circumference in subjects on an energy-restricted diet

\begin{tabular}{lllll}
\hline $\begin{array}{l}\text { Change } \\
\text { from } \\
\text { baseline } \\
\text { (inches) }\end{array}$ & 4 weeks & I 2 weeks & 24 weeks & $\begin{array}{l}\text { Significance } \\
\text { versus } \\
\text { placebo }\end{array}$ \\
\hline Placebo & $-0.55 \pm 0.30$ & $-1.57 \pm 0.64$ & $-2.13 \pm 0.87$ & $* P<0.01$ \\
NuShape & $-2.10 \pm 0.32 *$ & $-3.58 \pm 0.49 *$ & $-4.27 \pm 0.64 *$ & \\
\hline
\end{tabular}

Notes: Data expressed as the mean \pm standard deviation change from baseline; *Significance versus placebo.

significantly greater decrease in insulin and a corresponding improvement in homeostatic assessment of insulin resistance (HOMA $_{\text {IR }}$, Table 5). In the absence of caloric restriction, the NuShape group exhibited decreases in plasma insulin at both 12 weeks and 24 weeks and an improvement in $\mathrm{HOMA}_{\mathrm{IR}}$ at 24 weeks, while no significant changes were found in the placebo group (Table 6). Treatments were without significant effect on circulating lipids.

\section{Discussion}

Results of these studies demonstrate that the NuShape nutraceutical combination results in significant fat loss in the absence of caloric restriction and markedly enhances weight and fat loss by $50 \%-80 \%$ over a 24 -week period when compared with a placebo control. These data are consistent with our recent demonstration that NuShape stimulates a $>30 \mathrm{~g}$ (about $300 \mathrm{kcal}$ ) increase in whole-body fat oxidation in obese subjects, ${ }^{8}$ and demonstrates that this increase in fat oxidation results in clinically meaningful changes in body composition and weight loss.

Moderate weight reduction in the range of 5\%-10\% of body weight results in changes in adipose tissue characteristics, including a reduced inflammatory profile, ${ }^{14,15}$ and was reported to result in a 59\% reduction in the odds of having metabolic syndrome after one-year assessment. ${ }^{16}$ However, lifestyle changes such as caloric restriction and physical exercise are difficult to incorporate in the daily routine of most people. On the other hand, available pharmacotherapy risks systemic side effects, leading to discomfort, limited use, and/or withdrawal from the market. ${ }^{17}$ Therefore, finding safe alternatives to support

Table 4 Effects of NuShape ${ }^{T M}$ on body fat during weight maintenance

\begin{tabular}{lcll}
\hline $\begin{array}{l}\text { Change from } \\
\text { baseline (kg) }\end{array}$ & I 2 weeks & 24 weeks & $\begin{array}{l}\text { Significance } \\
\text { versus placebo }\end{array}$ \\
\hline Placebo & $0.04 \pm 0.51$ & $-0.02 \pm 0.43$ & $* P<0.01$ \\
NuShape & $-1.12 \pm 0.36^{*}$ & $-1.82 \pm 0.70 *$ & \\
\hline
\end{tabular}

Note: *Significance versus placebo.
Table 5 Effects of NuShape ${ }^{T M}$ on glucose, insulin, and HOMA $\mathrm{H}_{\mathbb{R}}$ in subjects on an energy restricted diet

\begin{tabular}{clll}
\hline $\begin{array}{l}\text { Change from } \\
\text { baseline }\end{array}$ & I 2 weeks & 24 weeks & Significance \\
\hline $\begin{array}{lll}\text { Insulin }(\mu \mathrm{U} / \mathrm{mL}) \\
\text { Placebo }\end{array}$ & $-1.22 \pm 1.06$ & $-2.11 \pm 0.95^{*}$ & $\begin{array}{l}* P<0.05 \\
\text { versus baseline }\end{array}$ \\
NuShape & $-3.40 \pm 0.9 *$ & $-5.02 \pm 0.84^{*}$ & $\begin{array}{l}* P<0.005 \\
\text { versus baseline } \\
\text { and placebo }\end{array}$ \\
$\begin{array}{l}\text { HOMA } \\
\text { Placebo }\end{array}$ & $-0.33 \pm 0.37$ & $-0.81 \pm 0.26^{*}$ & $\begin{array}{l}* P<0.05 \\
\text { versus baseline }\end{array}$ \\
NuShape & $-0.62 \pm 0.33^{*}$ & $-1.14 \pm 0.48^{*}$ & $\begin{array}{l}* P<0.0 \mathrm{I} \\
\text { versus baseline } \\
\text { and placebo }\end{array}$ \\
\hline
\end{tabular}

Notes: Data expressed as the mean \pm standard deviation change from baseline; *Significance.

Abbreviation: $\mathrm{HOMA}_{\mathbb{I R}}$, insulin $(\mu \mathrm{U} / \mathrm{mL}) \times$ glucose $(\mathrm{mM}) / 22.5$.

weight and fat loss and improve metabolic health are of great importance.

Adiposity is associated with adipocyte mitochondrial dysfunction, resulting in an increase in oxidative and inflammatory stress that contributes to insulin resistance, diabetes, and other chronic metabolic diseases. ${ }^{18-20}$ Visceral fat makes a greater contribution than subcutaneous fat to the secretion of proinflammatory cytokines and is therefore associated with a greater risk of metabolic dysregulation. ${ }^{21}$ The NuShape treatment produced a significantly greater loss in waist circumference than did the placebo during energy restriction, suggesting a loss of visceral fat. In our previous study, we demonstrated that use of NuShape resulted in reductions of oxidative and inflammatory stress biomarkers, such as plasma malondialdehyde, 8 -isoprostane F-2 $\alpha$, tumor necrosis factor- $\alpha$, and C-reactive protein, as well as an increase in the anti-inflammatory marker adiponectin after 4 weeks, even in the absence of weight loss. ${ }^{8}$ Thus, this leucine-B6 mixture appears to reduce visceral adiposity and attenuate the associated metabolic dysregulation.

Table 6 Effects of NuShape ${ }^{\mathrm{TM}}$ on glucose, insulin, and HOMA during weight maintenance

\begin{tabular}{lccl}
\hline $\begin{array}{l}\text { Change from } \\
\text { baseline }\end{array}$ & I 2 weeks & 24 weeks & $\begin{array}{l}\text { Significance } \\
\text { versus placebo }\end{array}$ \\
\hline $\begin{array}{l}\text { Insulin }(\mu \mathrm{U} / \mathrm{mL}) \\
\quad \text { Placebo }\end{array}$ & $0.46 \pm 0.95$ & $0.85 \pm 1.08$ & $* P<0.01$ \\
$\quad \begin{array}{l}\text { NuShape } \\
\text { HOMA }\end{array}$ & $-2.13 \pm 1.07^{*}$ & $-3.44 \pm 1.26^{*}$ & \\
$\quad \begin{array}{lll}\text { Placebo } \\
\text { NuShape }\end{array}$ & $-0.14 \pm 0.58$ & $0.42 \pm 0.32$ & $* P<0.05$ \\
\hline
\end{tabular}

Notes: Data expressed as the mean \pm standard deviation change from baseline; *Significance versus placebo.

Abbreviation: $\mathrm{HOMA}_{\mathbb{I R}}$, insulin $(\mu \mathrm{U} / \mathrm{mL}) \times$ glucose $(\mathrm{mM}) / 22.5$. 
5' AMP-activated protein kinase (AMPK) plays an important role in the development of insulin resistance because it regulates glucose and fat metabolism in response to nutrient status. ${ }^{22}$ Moreover, it converges with the SIRT pathways on peroxisome proliferator-activated receptor- $\gamma$ coactivator (PGC)-1 $\alpha$ activation, leading to increased mitochondrial function. ${ }^{23,24}$ Recent data suggest that decreases in AMPK and SIRT1 activity may be one of the responsible factors distinguishing insulin-resistant from insulin-responsive individuals with severe obesity. ${ }^{25,26}$ Indeed, AMPK activity was found to be decreased in obese insulin-resistant patients compared with obese insulin-sensitive patients, ${ }^{26}$ and activation of AMPK improves symptoms of impaired glucose homeostasis and insulin resistance. ${ }^{27-29}$ Similarly, treatment with SIRT1 activators has been shown to improve mitochondrial function and to protect mice against dietinduced obesity and insulin resistance. ${ }^{30,31}$ We previously found that leucine stimulates SIRT1 and SIRT1-dependent pathways, resulting in increased mitochondrial mass and fat metabolism in muscle cells and adipocytes. ${ }^{1,2}$ Consistent with this, our in vitro data indicate that the combination of leucine and B6 improves the oxidative capacity of cells, which results in an up to $80 \%$ increase in fatty acid oxidation in muscle and fat cells, measured as palmitate-induced oxygen consumption rate, as well as increases in adipocyte phospho-AMPK (Thr 172) and PGC-1 $\alpha$ protein expression and mitochondrial biogenesis (Supplementary Figure 1), indicating an increase in oxidative capacity. Although B6 may not directly synergize with leucine to increase fatty acid oxidation in muscle cells (Supplementary Figure 1D), it exerts synergistic effects with leucine in adipocytes, serving to both inhibit lipid storage ${ }^{8}$ and synergistically increase fatty acid oxidation.

SIRT1 and AMPK are sensors of signal nutrient/energy depletion and mobilize catabolic systems to generate necessary energy. In contrast, the mTOR system senses nutrient/energy abundance and signals an anabolic response (reviewed by Lopez-Otin et $\mathrm{al}^{32}$ ), and leucine is well known to stimulate mTOR. ${ }^{33}$ Notably, the SIRT1/AMPK system suppresses mTOR signaling, raising the question of the roles of these counter-regulatory systems in our observations. Schriever et $\mathrm{al}^{33}$ recently provided evidence to indicate that leucine, rather than downstream leucine catabolic products, is responsible for mTORC1 activation. In contrast, we have found a minor leucine downstream catabolic product ( $\beta$-hydroxy- $\beta$-methylbutyrate) to mediate leucine stimulation of mitochondrial biogenesis and fatty acid oxidation. ${ }^{34,35}$ Moreover, these effects were independent of mTOR, because they were maintained during mTOR inhibition with rapamycin. ${ }^{34}$

This study was designed as a follow-up of our previous trial $^{8}$ to assess the long-term effects of the NuShape combination in both weight maintenance and weight reduction. Despite the small number of subjects in each group, which limits interpretation of the data, the results were highly significant and in agreement with our previous in vivo and in vitro data.

\section{Conclusion}

The combination of leucine and pyridoxine found in NuShape provides a safe strategy to improve oxidative capacity and thereby significantly augments weight and fat loss.

\section{Author contributions}

$\mathrm{MBZ}$ designed and conducted the clinical studies. MBZ and $\mathrm{AB}$ were involved in data analysis and drafting the manuscript.

\section{Disclosure}

Financial support for this study was provided by NuSirt Sciences, Inc. Both authors are employees and stockholders of NuSirt Sciences, Inc.

\section{References}

1. Sun $X$, Zemel M. Leucine and calcium regulate fat metabolism and energy partitioning in murine adipocytes and muscle cells. Lipids. 2007; 42:297-305.

2. Sun X, Zemel MB. Leucine modulation of mitochondrial mass and oxygen consumption in skeletal muscle cells and adipocytes. Nutr Metab (Lond). 2009;6:26.

3. Macotela Y, Emanuelli B, Bang AM, et al. Dietary leucine - an envrionmental modifier of insulin resistance acting on multiple levels of metabolism. PLoS One. 2011;6:e21187.

4. Donato J Jr, Pedrosa RG, Cruzat VF, Pires IS, Tirapegui J. Effects of leucine supplementation on the body composition and protein status of rats submitted to food restriction. Nutrition. 2006;22:520-527.

5. Zhang Y, Guo K, LeBlanc RE, Loh D, Schwartz GJ, Yu YH. Increasing dietary leucine intake reduces diet-induced obesity and improves glucose and cholesterol metabolism in mice via multimechanisms. Diabetes. 2007;56:1647-1654.

6. Bruckbauer A, Zemel MB. Effects of dairy consumption on SIRT1 and mitochondrial biogenesis in adipocytes and muscle cells. Nutr Metab (Lond). 2011;8:91.

7. Bruckbauer A, Zemel MB, Thorpe T, et al. Synergistic effects of leucine and resveratrol on insulin sensitivity and fat metabolism in adipocytes and mice. Nutr Metab (Lond). 2012;9:77.

8. Zemel MB, Bruckbauer A. Effects of a leucine and pyridoxine-containing nutraceutical on fat oxidation, and oxidative and inflammatory stress in overweight and obese subjects. Nutrients. 2012;4:529-541.

9. Xue B, Zemel M. Relationship between human adipose tissue agouti and fatty acid synthase (FAS). J Nutr. 2000;130:2478-2481.

10. Kim J, Kiefer L, Woychik R, et al. Agouti regulation of intracellular calcium: role of melanocortin receptors. Am J Physiol. 1997;272: E379-E384.

11. Xue B, Greenberg A, Kraemer F, Zemel M. Mechanism of intracellular calcium $([\mathrm{Ca} 2+] \mathrm{i})$ inhibition of lipolysis in human adipocytes. FASEBJ. 2001;15:2527-2529. 
12. Xue B. The agouti gene product inhibits lipolysis in human adipocytes via a Ca2+-dependent mechanism. FASEB J. 1998;12:1391-1396.

13. Shi H, Moustaid-Moussa N, Wilkison W, Zemel M. Role of the sulfonylurea receptor in regulating human adipocyte metabolism. FASEB J. 1999;13:1833-1838.

14. Rossmeislova L, Malisova L, Kracmerova J, et al. Weight loss improves adipogenic capacity of human preadipocytes and modulates their secretory profile. Diabetes. 2013;62:1990-1995.

15. Olszanecka-Glinianowicz M, Chudek J, Szromek A, ZahorskaMarkiewicz B. Changes of systemic microinflammation after weight loss and regain - a five-year follow up study. Endokrynol Pol. 2012; 63:432-438.

16. Phelan S, Wadden TA, Berkowitz RI, et al. Impact of weight loss on the metabolic syndrome. Int J Obes (Lond). 2007;31:1442-1448.

17. Colon-Gonzalez F, Kim GW, Lin JE, Valentino MA, Waldman SA. Obesity pharmacotherapy: what is next? Mol Aspects Med. 2013;34: 71-83.

18. Capurso C, Capurso A. From excess adiposity to insulin resistance: the role of free fatty acids. Vascul Pharmacol. 2012;57:91-97.

19. Boden G. Obesity and free fatty acids. Endocrinol Metab Clin North Am. 2008;37:635-646, viii-ix.

20. Medina-Gomez G. Mitochondria and endocrine function of adipose tissue. Best Pract Res Clin Endocrinol Metab. 2012;26:791-804.

21. Fujihara S, Mori H, Kobara H, et al. Metabolic syndrome, obesity, and gastrointestinal cancer. Gastroenterol Res Pract. 2012;2012:483623.

22. Srivastava RA, Pinkosky SL, Filippov S, Hanselman JC, Cramer CT, Newton RS. AMP-activated protein kinase: an emerging drug target to regulate imbalances in lipid and carbohydrate metabolism to treat cardio-metabolic diseases. J Lipid Res. 2012;53:2490-2514.

23. Scarpulla RC. Metabolic control of mitochondrial biogenesis through the PGC-1 family regulatory network. Biochim Biophys Acta. 2011;1813: 1269-1278.

24. Canto C, Gerhart-Hines Z, Feige JN, et al. AMPK regulates energy expenditure by modulating NAD+ metabolism and SIRT1 activity. Nature. 2009;458:1056-1060.
25. Xu XJ, Pories WJ, Dohm LG, Ruderman NB. What distinguishes adipose tissue of severely obese humans who are insulin sensitive and resistant? Curr Opin Lipidol. 2013;24:49-56.

26. Gauthier MS, O’Brien EL, Bigornia S, et al. Decreased AMP-activated protein kinase activity is associated with increased inflammation in visceral adipose tissue and with whole-body insulin resistance in morbidly obese humans. Biochem Biophys Res Commun. 2011;404: 382-387.

27. Bergeron R, Previs SF, Cline GW, Perret P, Russell RR 3rd, Young LH, Shulman GI. Effect of 5-aminoimidazole-4-carboxamide-1-beta-Dribofuranoside infusion on in vivo glucose and lipid metabolism in lean and obese Zucker rats. Diabetes. 2001;50:1076-1082.

28. Pold R, Jensen LS, Jessen N, et al. Long-term AICAR administration and exercise prevents diabetes in ZDF rats. Diabetes. 2005;54:928-934.

29. Cool B, Zinker B, Chiou W, et al. Identification and characterization of a small molecule AMPK activator that treats key components of type 2 diabetes and the metabolic syndrome. Cell Metab. 2006;3:403-416.

30. Lagouge M, Argmann C, Gerhart-Hines Z, et al. Resveratrol improves mitochondrial function and protects against metabolic disease by activating SIRT1 and PGC-1alpha. Cell. 2006;127:1109-1122.

31. Feige JN, Lagouge M, Canto C, et al. Specific SIRT1 activation mimics low energy levels and protects against diet-induced metabolic disorders by enhancing fat oxidation. Cell Metab. 2008;8:347-358.

32. Lopez-Otin C, Blasco MA, Partridge L, Serrano M, Kroemer G. The hallmarks of aging. Cell. 2013;153:1194-1217.

33. Schriever SC, Deutsch MJ, Adamski J, Roscher AA, Ensenauer R. Cellular signaling of amino acids towards mTORC1 activation in impaired human leucine catabolism. J Nutr Biochem. 2013;24:824-831.

34. Stancliffe RA, Eades M, Smart K, Zemel MB. Role of mTOR and $\beta$-hydroxy- $\beta$-methylbutyrate (HMB) in leucine stimulation of muscle mitochondrial biogenesis and fatty acid oxidation. FASEB J. 2011; 25:601.1.

35. Stancliffe RA, Zemel MB. Role of $\beta$-hydroxy- $\beta$-methylbutyrate (HMB) in leucine stimulation of muscle mitochondrial biogenesis. FASEB J. 2012;26:251.6. 


\section{Supplementary figure}

A

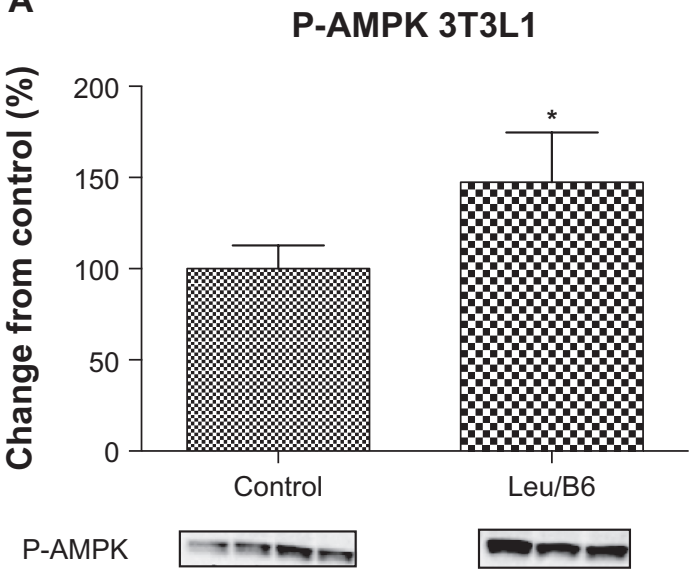

B

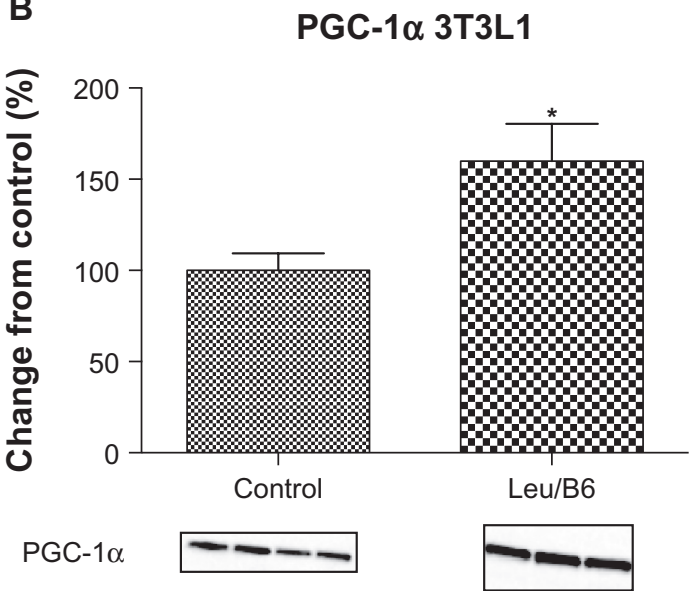

C

\section{Mitochondrial biogenesis in 3T3L1}

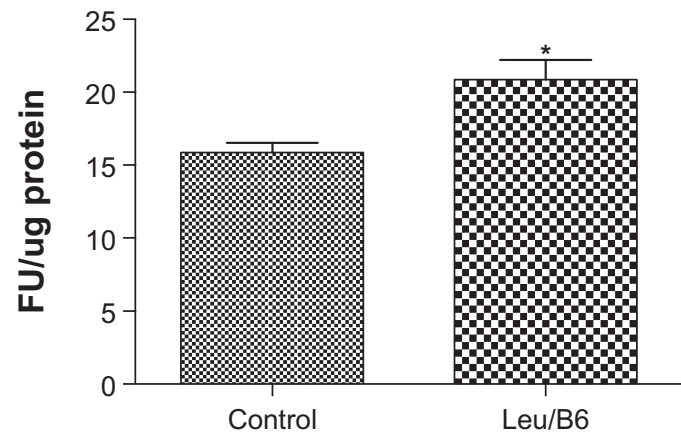

D

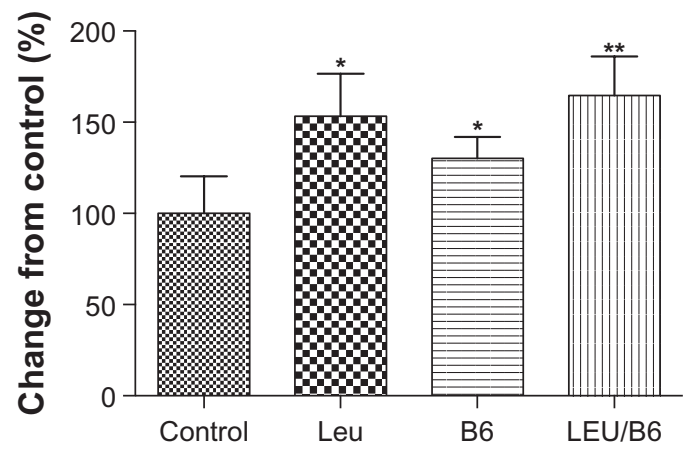

Figure SI Effects of leucine-B6 combination on AMPK, PGC- $\mid \alpha$, mitochondrial mass, and fatty acid oxidation. Differentiated adipocytes and C2CI2 muscle cells were treated with the treatments indicated for 24 hours. (A) Phospho (Thr 172)-AMPK and (B) PGC-I $\alpha$ protein expression was detected by Western blot and quantitatively analyzed. (C) Mitochondrial mass was measured by fluorescence ( $485 \mathrm{~nm}$ excitation and $520 \mathrm{~nm}$ emission) using the fluorophore, nonyl acridine orange (Life Technologies, Grand Island, NY, USA). (D) Oxygen consumption rate was measured after injection of $200 \mu \mathrm{M}$ palmitate, indicating fatty acid oxidation. Data are represented as the mean \pm standard error of the mean $(\mathbf{A}-\mathbf{C})$ or mean \pm standard deviation $(\mathbf{D})(n=6)$.

Notes: *Significant difference compared with control; **significant difference compared with control and B6 $(P \leq 0.05)$.

Abbreviations: AMPK, 5' AMP-activated protein kinase; Leu, leucine; CTRL, control; PGC, peroxisome proliferator-activated receptor- $\gamma$ coactivator; FU, fluorescent units.

Diabetes, Metabolic Syndrome and Obesity: Targets and Therapy

Dovepress

\section{Publish your work in this journal}

Diabetes, Metabolic Syndrome and Obesity: Targets and Therapy is an international, peer-reviewed open-access journal committed to the rapid publication of the latest laboratory and clinical findings in the fields of diabetes, metabolic syndrome and obesity research. Original research, review, case reports, hypothesis formation, expert opinion and commentaries are all considered for publication. The manuscript management system is completely online and includes a very quick and fair peer-review system, which is all easy to use. Visit http://www.dovepress.com/testimonials.php to read real quotes from published authors. 